\title{
PHOTODYNAMIC THERAPY IN THE TREATMENT OF GLIOMA
}

\author{
T.S. Zavadskaya \\ R.E. Kavetsky Institute of Experimental Pathology, Oncology and Radiobiology, \\ NAS of Ukraine, Kyiv 03022, Ukraine
}

\begin{abstract}
The review presents the data on the use of photodynamic therapy (PDT) for the treatment of patients with malignant brain tumors. One and two-year survival rate and an increase in overall median survival of PDT-treated patients compared with standard treatment indicate a promising prospects for PDT in neurooncology.
\end{abstract}

Key Words: glioblastoma, photodynamic therapy, photosensitizer, chlorin e6.

The stable increase in incidence and mortality of the primary and metastatic brain tumors (BTs), with an average of $2-3 \%$ of all neoplasmas, is an urgent issue of neurooncology representing one of the most extensive areas of neurosurgery $[1,2]$.

The World Health Organization estimates that currently there are more than 120 clinical nosological forms of malignant tumors of the brain [3]. Gliomas account for about $77 \%$ of primary malignant BTs and include astrocytomas (astrocytoma, anaplastic astrocytoma - AA, glioblastoma multiforme), oligodendrogliomas and mixed gliomas. All gliomas are characterized by their ability to rapid proliferation, angiogenesis and invasive growth [4].

Glioblastoma multiforme (GBM) has the highest incidence and shortest patient survival of all BTs. The prognosis of these tumors remains poor, with most patients dying within one or two years after diagnosis [5].

One of the major causes of extreme difficulty in BT treatment is the presence of blood-brain and blood-tumor barriers. These barriers almost completely exclude the possibility of distant lymphatic and hematogenous metastasis outside the central nervous system but simultaneously act as a barrier for an active transport of most drugs to the tumor foci [6]. It is not a metastasizing disease although extracranial metastases are observed in 0.4 to $0.5 \%$ of glioblastoma patients [7].

Ongoing fundamental advances in the delivery of therapeutics through the blood-brain barrier to the central nervous system combined with expanding knowledge of BT pathology provide the basis for the development of new, more effective approaches and improvement of existing methods for therapy of glioblastomas.

Glioblastoma shows considerable intratumoral phenotypic and molecular heterogeneity and con-

Submitted: May 26, 2015.

Correspondence: E-mail: zavadsky_solo@ukr.net

Abbreviations used: AA - anaplastic astrocytoma; 5-ALA - de-

rivatives of 5-aminolevulinic acid; BT - brain tumor; FGR -

fluorescence guided resection; $\mathrm{HpD}$ - hematoporphyrin de-

rivatives; GBM - glioblastoma multiforme; mTHPC - meta-

tetra(hydroxyphenyl)chlorin; PDD - photodynamic diagnosis;

PDT - photodynamic therapy; PS - photosensitizer. tains a population of cells with properties of cancer stem cells that contributes to tumor propagation, maintenance, and treatment resistance [8]. There is sufficient evidence that the normal neural stem cells can be converted into cancer stem cells and cause tumor growth. Cancer stem cells in glial tumors are heterogeneous population, among which there are cells that induce the second tumor growth in the brain ( 100 cells already causing tumor growth), as well as able to migrate throughout the brain parenchyma and form the simple capillaries. They are not very sensitive to temozolomide - only sublethal doses inhibit their proliferation. Irradiation of glial tumor in therapeutic dose range does not affect the cancer stem cells, low-dose irradiation increases aggressiveness and resistance of tumor [9].

New advances suggest new potential targets for the treatment of GBMs. In 2012 the Nobel Prize in Physiology or Medicine was awarded to John Gurdon and Shinya Yamanaka for the discovery that mature cells can be reprogrammed to become pluripotent capable of developing into all cells and tissues of the body including cancer stem cells [10]. Scientists have found evidence that the specialization of cells may be reversible. In parallel, researchers at the Salk Institute for Biological Studies (California) have found that mature cortical neurons are able to return to the immature state and develop into an aggressive type of $\mathrm{BT}$, which, as previously thought, develop only from neural stem or glial cells. "One of the reasons for the lack of clinical advances in GBM has been the insufficient understanding of the underlying mechanisms by which these tumors originate and progress," - says Inder Verma, a professor of Genetics Laboratory [11]. It was found that upon oncogenic insult, such as loss of NF1 and p53, terminally differentiated glia or neurons can dedifferentiate into tumor initiating neuro-progenitor cells. These cells can self-renew and also differentiate into astrocytes, neurons and oligodendrocytes. Tumor initiating of neuro-progenitor cells can also transdifferentiate into endothelial cells. In a similar fashion, normal neuro-progenitor cells can also differentiate into astrocytes, neurons and oligodendrocytes and transdifferentiate into endothelial cells [12]. Thereby new revolutionary theories allowed moving away from the old dogmas, as to the nature of the tumor, and the 
ineffectiveness of the various methods of glioblastomas' treatment. Through therapeutic agents to transform cancer stem cells into differentiated population deprived of the ability to migrate (taking into account the possibility of divergent processes, proven experimentally) for prevention the second growth after the standard treatment.

Immuno- and virus oncolytic therapy, nanotechnology, methods capable of causing local hyperthermia, photodynamic therapy (PDT), which has a local and systemic antitumor effect, the new antiangiogenic agents are likely to affect the basic mechanism of local recurrence. Treatment of high grade brain malignancies includes surgery in combination with radiation therapy, chemotherapy and immunotherapy, and local (interstitial) hyperthermia, nano- and antiangiogenic therapy. Recently, there have appeared major ways to improve the prognosis and quality of life of patients with BTs including multimodal neuronavigation and supra-maximum tumor resection [13]. Multimodal neuronavigation allows the integration of preoperative anatomic and functional data with intraoperative information. This approach includes functional magnetic resonance (MRI) and diffusion tensor imaging (DTI) in the planning of volume of operations, ultrasound and computer tomography, MRI and direct (sub)cortical stimulation during surgery, the practice of awake craniotomy. But functional MRI and DTI is inaccurate image-to-patient mapping as well as brain shifts during surgery that is impossible to prevent.

Unfortunately, most of the BTs are diagnosed at the advanced stages, and surgery is not always being radical due to pronounced ability of the tumor to the infiltrative growth and involvement of functionally important parts of the brain in the malignant process, and arising neurological deficit doesn't allow attributing the surgical treatment to prognostically defensible methods. Even in the case of maximal tumor resection in the perifocal area in $96 \%$ of patients the recurrence of tumor growth indicated in a short period of time [14].

According to Bernstein and Bampoe (2000) the survival of the majority of operated patients with high grade glioblastomas doesn't exceed 12 months, and only $3.5 \%$ of them live more than 5-years [15]. In a study of Ries et al. (2006), the median survival in operated patients was 18.6 months [16].

Standard regimen of radiation therapy is a fractional distance gamma-therapy with 5-day cycles of exposure with single focal dose 1.2-2.65 Gy and a total focal dose 60-65 Gy (ESMO, 2007). The median survival of patients after radiotherapy and regimen of fractionation was 10 months [17]. Some authors have studied the possibility of increasing the total focal dose up to 80-90 Gy. As a result, the median survival of patients with glioblastoma reached 16.2 months for the high-dose group and 12.4 months for the conventional group; 2-year survival was $38.4 \%$ for the highdose group and $11.4 \%$ for the conventional group. Survival did not differ between those that received 80 Gy radiotherapy and those that received 90 Gy [18] .
In the recent years, the most promising directions in radiotherapy are considered to be the corpuscular (boron-neutron capture) and intraoperative radiation therapy, stereotactic interstitial radiation with the implantation of radioactive sources (iridium-192, palladium-103, and others) to the tumor, stereotactic radiosurgery and brachytherapy [19-21].

Chemotherapy in combination with pre- and postoperative radiation therapy is the basic therapy for patients with brain gliomas [22]. According to Ushio et al. (1999), the use of intra-arterial infusion in 50-75\% of patients with glioblastomas contributed to an increase in the duration of remission and the number of regressed tumors [23].

In the recent years, the method of intratumoral (interstitial) chemotherapy of BTs is widely used in the clinics of USA, Germany, Japan, Belarus and others with using of different cytotoxic drugs deposited in absorbable polymer carriers with programmed release of them in the area of implantation. Sheleg et al. $(2000,2001)$ have developed the method of complex treatment. The complex treatment included the implantation of the film with cisplatin on the place of the removed tumor, followed by total irradiation of the brain (single focal dose 4 Gy, 20 Gy) in the first stage, and target radiotherapy to the area of tumor (single focal dose $2 \mathrm{~Gy}, 30 \mathrm{~Gy}$ ) - on the second stage. The authors noted a significant increase in median survival of patients - from 7.3 to 14.2 months, compared with patients treated with monotherapy as a radiotherapy (7.1 months) or local chemotherapy with cisplatin (3.7 months) [24, 25].

The big interest arise for research on the antitumor efficacy of the local (interstitial) hyperthermia in the treatment of BTs. Takahashi et al. [26] reported the results of using interstitial hyperthermia in the treatment of 36 patients ( 18 with glioblastoma, 18 with $A A$ ) in combination with an external gamma radiation (total focal dose $60 \mathrm{~Gy}$ ). Complete regression was achieved in 5 patients, partial - in 13, the stabilization of tumor process - in 15 and progression of the disease in 3 patients.

Nanotechnology is another promising approach in the treatment of many malignant tumors including glial BTs. In 2009, there were first published results of complex treatment of 59 patients with recurrent gliomas by thermotherapy, with the introduction into tumor superparamagnetic nanoparticles with followed course of neoadjuvant radiotherapy. This approach showed prognostically significant increase in median survival of patients up to 13.4 months [27].

Accumulating evidence has shown that prognosis for patients with malignant glioma remains extremely unfavorable. Even in the modern era, the population-based median survival is only approximately 10 months. The longest survival is achieved in patients who undergo gross total resection followed by radiotherapy and temozolomide, but the median survival in this population is still only 20 months [28]. In light of these meagre results there is significant room 
for innovative surgical methods and photodynamic technologies for increasing the extent of resection and improving upon the associated survival benefit.

Photodynamic techniques such as photodynamic diagnosis (PDD), fluorescence guided resection (FGR) and PDT are currently undergoing intensive clinical investigations as adjuvant treatment for malignant BTs [29-32]. Prerequisites for its wider use in neuro-oncology as an alternative method of therapy of malignant BTs are the results of many clinical and experimental studies that have proven a significant increase of patients survival and disease-free interval, and reducing the risk of severe neurological complications [31-37].

In 1980, early pioneering researchers in brain PDT had reported their series of post-resection glioma cavity PDT and predicted that future refinement of the technique may produce better tissue penetration and more radical glioma cell-kill [38]. The most encouraging results of the application of PDT were data presented by Kostron et al. in 1996 [39]. Over 310 patients suffering from primary or recurrent malignant BTs were reported in the above review to be treated with PDT following tumor resection in open clinical phase I/II trials. Variations in the treatment protocols make scientific evaluation difficult; however, there is a clear trend of increased median survival after surgical resection and one single photodynamic treatment. According to Kostron, the median survival after PDT for primary GBM (WHO grade IV) was 22 months and for recurrent GBM -9 months as compared to standard conventional treatment, in which median survival was 15 and 3 months, respectively [40].

In 2005, Stylli and Kaye reported one of the largest series of PDT. They have treated over 350 patients with different forms of glioma, including 136 patients with GBM and AA utilizing PDT as an adjuvant therapy. There was median survival of approximately 14.3 months for primary GBM patients with $28 \%$ survival more than 24 months and $22 \%$ of patients surviving long term beyond 60 months. Median survival for the patients with AA increased to 76.5 months. The results from this study were especially promising for recurrent GBM patients where $41 \%$ of these patients survived beyond 24 months and $37 \%$ beyond 36 months following repeat surgery. These authors also reported a review of the literature from 9 studies that showed similar results. It was concluded that PDT shows potential as a novel adjuvant therapy for glioma treatment along with chemotherapy and radiation therapy [41]. Published results of numerous studies indicated that PDT significantly increased the survival of patients with malignant gliomas and that brain PDT was well tolerated but there were several compounding factors that led to inconsistency and variability of the outcome in patients.

PDT is a method of local treatment of the tumor. The method is based on introducing a photosensitizer (PS), its selective accumulation in the tumor tissue and the subsequent interaction with light of appropriate wavelength that provides adequate penetration into biological tissues, which in the presence of oxygen causes a photochemically mediated destruction of tumor cells [29]. The mechanism of action in PDT involves the direct cytotoxic effects on the tumor, leading to necrosis and apoptosis of tumor cells as well as tumor microvascular damage due to evolving vascular stasis, thrombosis and hemorrhage leading to cell hypoxia and subsequent death [42]. It should also be noted that one of the targets for photodynamic treatment are macrophages, photoirradiation of which leads to the production of inflammatory mediators and cytokines (lymphokines, thromboxane, prostaglandin, tumor necrosis factor, etc.) which are important for the degradation of tumor stroma [33, 43-45]. Currently, PDT of BTs is used with various PSs such as hematoporphyrin derivatives $(\mathrm{HpD})$ - Photofrin ("QLT Photo Therapeutics", Canada), Photosan ("AXXO GmbH", Germany), Photohem (Moscow State University of Chemical Technology, Russia), Verteporfin ("Axcan Scandipharm", Norway); derivatives of 5-aminolevulinic acid (5-ALA) - Alasens (State Scientific Center "NIOPIK", Russia), Levulan ("DUSA Pharmaceuticals", USA), Metviks ("Photocure ASA", Norway) causing the induction of protoporphyrin IX synthesis in cells; derivatives of chlorin e6 - MACE (Japan), Foscan (metatetra(hydroxyphenyl)chlorin - MTHPC; "BioLitec", UK), Photolon ("Belmedpreparaty", Republic of Belarus), Photoditazine (LLC "BETA-GRAND", Russia). The promising PS is a synthetic aluminum sulfoftalotsianin - Photosense (State Scientific Center "NIOPIK", Russia).

Ideal PSs must be purged from impurities to selectively accumulate in tumor tissue and have the ability to cross the blood-brain barrier. PSs should also be localized in tumor tissue without absorbing in significant concentrations in healthy tissue and have a maximal cytotoxic activity against tumor cells by absorbing photons of light in the spectrum diapason of $650-700 \mathrm{~nm}$. It is important that PSs don't cause systemic toxicity and are rapidly excreted from the body [32, 34, 44]. Efficacy of the photodynamic damage of sensitized cell is defined by intracellular concentration of the sensitizer, its localization in the cell and its photochemical activity and the dose of laser irradiation. Selectivity of accumulation of PSs in BT - one of the key questions in the problem of increasing the effectiveness of PDT. It was found that after the introduction PSs are accumulated in all organs of the body, but tumor tissue has higher affinity $[33,46]$. Blood-brain barrier, which is an obstacle for the penetration of most drugs, is not an obstacle for PSs. It has been proved that the selectivity of accumulation of PSs in BT tissues varies over from 3:1 to 50:1 compared with normal tissues [32, 37].

Tumor cytoreduction is limited by the difficulty in distinguishing glioma infiltration from the normal brain during surgery and concerns over causing neurological deficits. This problem is can be partially solved by PDD. In 1998, a group of researchers in Germany reported the utilization of PDD and FGR to achieve 
maximum tumor removal safety. Coupling this technology with surgical microscope had led to improved completeness of the resection of the tumors [47]. The proof of principle for the better tumor visualization by fluorescence guidance was demonstrated in a large, multicenter phase III randomized controlled trial of 270 patients with high grade glioma, $88 \%$ of whom had GBM [48]. PDD, FGR have already been shown to help in removing the residual tumor. In $65 \%$ of cases, a gross total resection was achieved compared with a $36 \%$ rate when using conventional white light. This study combined the techniques of ALA and $\mathrm{HpD}$ induced fluorescence assisted surgical resection (PDD, FGR), PpIX spectroscopy and repetitive PDT with a total dose of up to $500 \mathrm{~J} / \mathrm{cm}^{2}$ divided into five fractions, and demonstrated that patients in the study group had significantly higher survival and quality of life compared to the control group [49].

Over the past decades, the literature has accumulated many conflicting data about the first experience with the application of PDT and PDD for BTs using different PSs. The most valuable long-term results of PDT in BTs are presented in the Table.

Table. Long-term results of BT PDT*

\begin{tabular}{|c|c|c|}
\hline Authors & $\begin{array}{l}\text { Diagnosis } \\
\text { (n) }\end{array}$ & Results \\
\hline Perria et al., & $\mathrm{GB}(3)$ & Survival rate was 6-44 weeks \\
\hline 1980 (cit. ex: [41]) & GS (1) & \\
\hline Kaye et al., 1987 & GS (19) & 13 patients lived from 1 to 16 months \\
\hline (cit. ex: [41]) & $A(3)$ & without recurrence \\
\hline Muller, Wilson, & $\mathrm{GB}(16)$ & The average disease-free period for $36 \%$ \\
\hline 1987 (cit. ex: [41]) & $A(13)$ & of patients was more than 26 months \\
\hline $\begin{array}{l}\text { Kostron et al., } \\
1987 \text { (cit. ex: [41]) }\end{array}$ & $\mathrm{GB}(16)$ & 6 patients lived up to 12 months \\
\hline Perria et al., & $\mathrm{GB}(2)$ & Control computer tomography after \\
\hline 1988 (cit. ex: [3]) & $\begin{array}{c}A(3) \\
\text { ODG (2) }\end{array}$ & $\begin{array}{l}9 \text { months in } 6 \text { patients didn't detect } \\
\text { signs of tumor growth }\end{array}$ \\
\hline $\begin{array}{l}\text { Kostron et al., } \\
1988 \text { (cit. ex: [3]) }\end{array}$ & $\mathrm{GB}(18)$ & 6 patients survived up to 22 months \\
\hline Pouer et al., & $\mathrm{AA}(4)$ & Disease-free period in 4 patients with \\
\hline 1991 (cit. ex: [41]) & $\begin{array}{l}\text { GS (1) } \\
\text { GB (1) }\end{array}$ & $\begin{array}{l}\text { AA }-45 ; 35 ; 8 \text { and } 6 \text { weeks. In a pa- } \\
\text { tient with GB }-27 \text { weeks, with GS - } \\
2 \text { weeks }\end{array}$ \\
\hline $\begin{array}{l}\text { Muller, Wilson, } \\
1995 \text { (cit. ex: [3]) }\end{array}$ & GB (56) & Average survival rate was 30 weeks \\
\hline Popovic et al., & GB (78) & In 38 patients with GB survival averaged \\
\hline 1995 (cit. ex: [3]) & $\begin{array}{c}\mathrm{AA}(24) \\
\mathrm{A}(7)\end{array}$ & $\begin{array}{l}24 \text { months; in } 40 \text { patients with recur- } \\
\text { rent GB - } 9 \text { months; in } 24 \text { patients with } \\
A A-20 \text { months, } 7 \text { patients with A un- } \\
\text { der continued observations }\end{array}$ \\
\hline Muller, Wilson, & GB (32) & In patients with GB survival rate \\
\hline 2000 (cit. ex: [3]) & $\begin{array}{l}\text { AA (14) } \\
\text { MMG (6) }\end{array}$ & $\begin{array}{l}\text { averaged } 31 \text { weeks, with } A A- \\
50 \text { weeks, with MMG - } 64 \text { weeks }\end{array}$ \\
\hline $\begin{array}{l}\text { Rosenthal et al., } \\
2003 \text { (cit. ex: [3]) }\end{array}$ & $\begin{array}{l}16 \text { recur- } \\
\text { rent } \mathrm{GB} \\
\mathrm{AA}(12)\end{array}$ & $\begin{array}{l}\text { In patients with GB survival rate was } \\
2-38 \text { months, with } A A-5-48 \text { months }\end{array}$ \\
\hline $\begin{array}{l}\text { Schmidt et al. } \\
2004 \text { (cit. ex: [3]) }\end{array}$ & GB (20) & Survival rate averaged 67 weeks \\
\hline Stylli, 2005 (cit. ex: & GB (78) & In patients with AA survival rate \\
\hline [3]) & $\mathrm{AA}(58)$ & $\begin{array}{l}\text { averaged is } 76.5 \text { months, with GB - } \\
14.3 \text { months ( } 5 \text {-year survival amounted } \\
\text { to } 63 \text { and } 22 \% \text {, respectively) }\end{array}$ \\
\hline $\begin{array}{l}\text { Muller, Wilson, } \\
2006 \text { (cit. ex: [3]) }\end{array}$ & GB (112) & $\begin{array}{l}\text { Average survival rate was } 30 \text { weeks } \\
\text { (1-year survival - in } 22 \% \text { of patients, } \\
\text { 2-year survival - in } 2 \% \text { ) }\end{array}$ \\
\hline Eljamel et al., & $\mathrm{GB}(13)$ & Average survival rate was 52.8 weeks \\
\hline
\end{tabular}

2008 (cit. ex:

Note:*A - astrocytoma, AA - anaplastic astrocytoma, GB - glioblastoma, GS - gliosarcoma, ODG - oligodendroglioma, MMG - mixed malignant glioma.
In the studies mentioned in Table HpDs were used. Disadvantages of $\mathrm{HpD}$ s are their insufficient selectivity, long period of persistence (particularly in the skin), as well as the maximum light absorption with a wavelength of about $400 \mathrm{~nm}$, while the better transmission in the biological tissues is achieved with wavelengths in the range of $650-800 \mathrm{~nm}$.

Currently, promising drugs are water-soluble chlorophyll derivatives - chlorins, bacteriochlorins and synthetic drugs - phthalocyanines, etiopurpurin, benzohlorin. In Europe mTHPC is widely used, which has high antitumor efficacy even when applied at low doses $(0.1-0.2 \mathrm{mg} / \mathrm{kg})$ and with radiation energy density of $10-40 \mathrm{~J} / \mathrm{cm}^{2}[44,50]$.

Kostron and Zimmermann et al. conducted clinical trials in a phase II study on the effectiveness of PDT for BTs using MTHPC. The median survival of patients was 9 months, and under the additional use of intraoperative fluorescence demarcation of tumor edges 13 months, that was two times more than in the control group (6 months) [44, 51, 52].

At the A.L. Polenov Russian Neurosurgical Institute (St. Petersburg), Olyushin et al. [34, 53-56] carried out clinical testing of a method of intraoperative PDT using chlorin e6 in 15 patients with malignant BTs. Photodithazine was administered intravenously at a dose of $1.0 \mathrm{mg} / \mathrm{kg}$ in the preoperative period, 1.5 hours before surgery. The laser radiation $(660 \mathrm{~nm})$ at a dose of $50-150 \mathrm{~J} / \mathrm{cm}^{2}$ was used. After irradiation with a laser beam scattered on the tumor bed laser beam focusing was carried out and the staged irradiation of tumor-bearing parts of the cortex of a small diameter at a distance from the main assembly, including the perivascular zone was performed. It has been achieved a greater degree of tumor tissue reduction avoiding additional surgical injury of the medulla. At the N.N. Petrov Institute of Oncology (St. Petersburg), the clinical trials of the chlorin e6 effectiveness in PDT of BTs were also carried out using laser radiation $(660 \mathrm{~nm})$ [55]. PS was administered intravenously at a dose of $0.5 \mathrm{mg} / \mathrm{kg}$. Light irradiation dose ranged from 160 to $400 \mathrm{~J} / \mathrm{cm}^{2}$. However, due to the small number of patients and significant variations in drug and irradiation doses the effectiveness of treatment was difficult to evaluate.

At the P.A. Gertsen Moscow Research Oncological Institute, since 2007 the efficacy of intraoperative PDT in conjunction with surgical treatment of BTs patients has been studied. 5-ALA was used as an inductor of protoporphyrin IX. Irradiation was performed using a semiconductor laser with wavelength of $635 \mathrm{~nm}$. The energy density of laser irradiation was within $60 \mathrm{~J} / \mathrm{cm}^{2}$. A substantial reduction in the incidence of recurrence (from $22 \%$ in patients of the control group to $4.7 \%$ in the study group) has been shown $[57,58]$.

In similar way, at Kavetsky Institute of Experimental Pathology, Oncology and Radiobiology (Kyiv, Ukraine), we treated two patients with recurrent GBMs of parietal and temporal brain regions (a male of 50 years and a woman of 60 years) [59]. PS Alasens was administered 
through a nasogastric tube for three hours before irradiation of the tumor bed at the rate of $60 \mathrm{mg} / \mathrm{kg}$ body weight. PDT was performed by "Lika-surgeon" with wavelength of $635 \mathrm{~nm}$ ("Photonics Plus", Cherkassy, Ukraine) using fractionation mode ( 1 min exposures 1 min interval) and irradiation dose of $100 \mathrm{~J} / \mathrm{cm}^{2}$. The man lived 24 months maintaining the ability to work for 18 months. The woman lived nine months and died of heart failure that occurred as a consequence of chemotherapy.

Numerous published reports indicate the increasing importance of PDT as an adjuvant for neurosurgical interventions. The series of clinical studies were carried out in which the fluorescence resulting from laser excitation of the PS was used for intraoperative tumor tissue monitoring during resection of glial neoplasms [47, 60-64]. With applying intraoperative PDT and PDD median survival of patients with BTs reaches 21 months [65]. However, since in the most of the studies there wasn't sufficient number of patients, it is difficult to definitely prove that the PDT and PDD of BTs strongly affect the prolongation of disease-free interval and median survival of patients.

Recently, in Belarus, on the basis of chlorin e6, a second-generation PS chlorin e6 has been developed. It has fairly fast and selective accumulation in the tumor tissue, comparatively high therapeutic and diagnostic efficacy, rapid clearance from the body (within 24 hours), a short period of increased skin phototoxicity and high stability during storage [66]. There are a number of experimental studies with chlorin e6 confirming its high PDT efficacy in glial tumors of rats. Eremeyev et al. [67, 68] at the Chelyabinsk State Institute of Laser Surgery conducted an experimental study of PDT efficacy using chlorin e6 for malignant glial tumors of the brain in rats to whom tumor tissues of human origin (glioblastoma Grade 3, AA) were transplanted. The author used diode laser with a wavelength of $660 \mathrm{~nm}$, power of $100 \mathrm{~mW}$ and power density of $44 \mathrm{~mW} / \mathrm{cm}^{2}$, which led to the necrosis of tumor tissue and the formation of local rumen in the area of laser irradiation in the early stages of observations. The authors noted the advantage of chlorin e6 use in PDT of glial tumors, compared with a number of other PSs, as to the high efficiency and the minimal risk of side effects associated with the drug accumulation in the skin and internal organs.

At the N.N. Blokhin Russian Cancer Research Center experimental studies of rat glial tumors PDT with a phthalocyanine PS Photosens $(3.5 \mathrm{mg} / \mathrm{kg})$ were conducted. Irradiation was carried out 24 hours after injection of PS using laser light with a wavelength of $675 \mathrm{~nm}$. Radiation power was $100 \mathrm{~mW}$ with exposition duration of $15 \mathrm{~min}$. Authors showed the reduction of tumor size by 3.4-fold in the study group compared to the control group. The findings suggest the efficacy of PDT with Photosens in the treatment of rat glioma and the expediency of further research employing the proposed method [68]. Ermakova et al. [57] used the rat glioma C6 to determine the effective- ness of PDT with Tiosens (absorption spectrum with maxima at $717 \mathrm{~nm}, 648 \mathrm{~nm}$ and $342 \mathrm{~nm}$ ). Accumulation level of Tiosens was evaluated by fluorescence method. Excitation of fluorescence with Tiosens was performed by laser with a wavelength of $720 \mathrm{~nm}$. Laser irradiation was performed at doses of $120 \mathrm{~J} / 5 \mathrm{~mm}^{2}$ and $60 \mathrm{~J} / 5 \mathrm{~mm}^{2}$. Lizomustin ((2-chloroethyl) nitrosoureido derivative of lysine amino acids) was administered intravenously once in a dose of $80 \mathrm{mg} / \mathrm{kg}$ in 3 hours after laser irradiation. Intraoperative PDT, conducted through craniotomy hole after partial tumor resection, followed by intravenous administration of Lizomustin, caused an increase in life span of rats by $84 \%$ compared to control animals, which was due to increase of vascular permeability of the tumor during the first three hours after PDT. In the study authors referred to earlier studies of Hirschberg et al. [70] who showed that after PDT with ALA the tumor vascular permeability significantly increased almost immediately after the laser irradiation and remained high for 72 hours. In experimental studies in vitro and in vivo the effectiveness of PDT of BTs using PSs chlorin e6, 5-ALA, $\mathrm{HpD}, \mathrm{mTHPC}$ also has been confirmed. In our previous experimental study [71], we have reported the results of rat glioma $\mathrm{C} 6$ and 101.8 photodynamic therapy with chlorin e6. Three basic approaches were used: photodynamic blood modification (PBM) with chlorin e6, local photodynamic therapy of BTs and combination of the two above-mentioned methods. The effectiveness of each treatment method was compared with control groups. We have shown promising results of PBM with chlorin e6, both as monotherapy and as combination therapy with local photodynamic tumor therapy. Obtained results indicated the need for further optimization of irradiation doses, number of treatment procedures and intervals between them. In published studies on effectiveness of PDT, there is no information available about the development of resistance to numerous sessions of PDT, which suggests the possibility of repeated treatments of tumor cells, not removed during surgery. Further studies with the development of new experimental models of PDT, which would apply repeated exposures of the tumor are needed.

\section{FUTURE PERSPECTIVES}

In PDT of glioma various strategies are conceivable. Before closing the resection cavity its illumination with the appropriate light is a straightforward option. The debate about improved treatment efficacy by light fractionation is ongoing. Further in-depth investigations with the creation of new experimental models of PDT, which would allow repeated exposures of the tumor are needed. Also, proposed so-called metronomic PDT involves prolonged low-dose illumination of the tumor cavity in the postoperative days. One novel approach would be the use of an implantable telemetric light delivery and monitoring system for controlled metronomic PDT [72].

Interstitial PDT deserves of special attention. For interstitial PDT, the hyperthermia limit has been shown 
below $400 \mathrm{~mW} / \mathrm{cm}^{2}$ fiber diffuser output. It is possible to expect intratumoral temperature rises of between 5 to $10^{\circ} \mathrm{C}$ within $2.5-4.5 \mathrm{~mm}$ tissue depth from the diffuser. It has been shown that if the surface irradiance exceeds $200 \mathrm{~mW} / \mathrm{cm}^{2}$, hyperthermia may synergistically contribute to the overall treatment effect [73].

Novel intraoperative fluorescence imaging systems and probes including fluorescein sodium, dyecontaining nanoparticles, and targeted nanoprobes, are being studied to improve the specificity and selectivity of intraoperative fluorescence during PDT. For example, chlorin-loaded nanoparticles were designed to utilize the EPR-based passive targeting mechanisms in brain cancers [74].

GBM is very invasive tumor and the inability to remove infiltrating tumor cells during surgical resection is the primary cause of relapse. Therefore, development of new PDT approaches and specific inhibitors of GBM invasion should be of a high priority. Novel mechanisms driving baseline and antiangiogenesis induced GBM invasion, as well as alternative neovascularization, will be investigated.

\section{CONCLUSION}

Accumulated considerable experience of PDT applications in cancers, particularly for malignant tumors of the skin, lungs and gastrointestinal tract, suggests that there is a reason to believe that PDT is a most effective method to prevent local spread of tumor cells. It is well known that neuroectodermal tumors have the ability to local expansion in the brain tissue and infiltrative growth, whereas metastases of these tumors outside the central nervous system are rare. The spread of tumor cells occurs infiltrative, mainly through membranes of the brain, cerebrospinal fluid conductor paths, as well as perivascular and perineural spaces at a distance of 3-4 $\mathrm{cm}$ from the primary tumor. The blood-brain barrier not only contributes to the selective local spread of tumors, but also prevents the full effects of chemotherapy. Thus, the duration of disease-free period and the survival of patients with glioma depend on the local propagation speed of the pathological process. PDT as a treatment method has a local impact, aims to increase a zone of tumor destruction during operation, which allows to improve survival outcome and life quality of patients with glioma.

\section{REFERENCES}

1. Enam SA, Rock JP, Rosenblum ML. Malignant glioma. Neurooncology. New York: The Essentials, 2000; 31: 309-18.

2. Grant R. Overview brain tumor diagnosis and management. J Neurol Neurosurg Psychiatry 2004; 75: 18-3.

3. Tserkovsky DÀ. Photodynamic therapy of malignant brain tumors: present and future. Bel Oncol J 2011; 5: 129_ 38 (in Russian).

4. Cohen AL, Colman H. Glioma biology and molecular markers. Cancer Treat Res 2015; 163: 15-30.

5. Urbanska K, Sokotowska J, Szmidt M, Sysa P. Glioblastoma multiforme - an overview. Contemp Oncol (Pozn) 2014; 18: 307-2.
6. Woodworth GF, Dunn GP, Nance EA, et al. Emerging insights into barriers to effective brain tumor therapeutics. Front Oncol 2014; doi: 10.3389/fonc.2014.00126.

7. Lun M, Lok E, Gautam S, et al. The natural history of extracranial metastasis from glioblastoma multiforme. J Neurooncol 2011; 105: 261-73.

8. Sundar SJ, Hsieh JK, Manjita S, et al. The role of cancer stem cells in glioblastoma. Neurosurg Focus 2014; 37; doi: 10.3171/2014.9.FOCUS14494.

9. Lisyany NI. The modern technologies of conservative treatment of gliomas. In: Cerebral gliomas. Under red YA Zozulya. Kyiv: Ltd. "Express-Polygraph”, 2007: 383569 (in Russian).

10. Holmes D. Stem cell scientists share 2012 Nobel Prize for medicine. Lancet 2012; 380: 1295.

11. Soda Y, Marumoto T, Friedmann-Morvinski D, et al. Transdifferentiation of glioblastoma cells into vascular endothelial cells. Proc Natl Acad Sci USA 2011; 108: 4274-80.

12. Soda Y, Myskiw C, Rommel A, Verma I. Mechanism of neovascularization and resistance to anti-angiogenic therapies in glioblastoma multiforme. J Mol Med 2013; 91: 439-48.

13. Wolbers JG. Novel strategies in glioblastoma surgery aim at safe, supra-maximum resection in conjunction with local therapies. Chin J Cancer 2014; 33: 8-15.

14. Caspar LF, Fisher BJ, Macdonald DR, et al. Supratentorial malignant glioma: patterns of recurrence and implication for external beam local treatment. Int J Radiat Oncol Biol Phys 1992; 24: 55-7.

15. Bernstein M, Bampoe J. Low-grade gliomas. Neurooncology. New York: The Essentials 2000; Ch 30: 302-08.

16. Ries LG, Eisner MP, Kosary CL. SEER cancer statistics review, 1975-002. Bethesda, MD: Nat Cancer Inst, 2005 (http://seer.cancer.gov/csr/1975_2002).

17. Buckner JC, Ballman KV, Michalak JC, et al. Phase III trial of Carmustine and Cisplatin compared with Carmustine alone and standard radiation therapy or accelerated radiation therapy in patients with glioblastoma multiforme: North Central Cancer Treatment Group 93-72-52 and Southwest Oncology Group 9503. J Clin Oncol 2006; 24: 3871-9.

18. Tanaka $M$, Ino $Y$, Nakagawa $K$, et al. High-dose conformal radiotherapy for supratentorial glioma: a historical comparison. Lancet Oncol 2005; 6: 953-60.

19. Nakagava $Y$, Pooh $K$, Kobayashi $T$, et al. Clinical review of the Japanese experience with boron neutron capture therapy and a proposed strategy using epithermal neutron beam. J Neurooncol 2003; 62: 87-9.

20. Schueller P, Micke O, Palkovic S, et al. 12 years experience with intraoperative radiotherapy [IORT] of malignant gliomas. Strahlenter Oncol 2005; 181: 500-6.

21. Vitaz TW, Warnke PC, Tabar V, et al. Brachytherapy for brain tumors. J Neurooncol 2005; 73: 71-86.

22. Mikkelsen T. Cytostatic agents in the management of malignant gliomas. Cancer Control 1998; 5: 52-2.

23. Ushio Y, Takagachi Y, Nakamura H. Intra-arterial therapy for brain tumors. In: Arterial infusion chemotherapy. Jpn J Cancer Chemother Pub Inc 1999; 3: 139-50.

24. Korotkevich EA. Complex treatment of malignant gliomas of the brain using a local chemotherapy by deposited cisplatin. Vestn Health Care 2001; 2: 11-4 (in Russian).

25. Sheleg S. Interstitial chemotherapy of newly diagnosed glioblastoma multiform with cisplatin polymer implants. Ann Oncol 2000; 3: 450-6.

26. Takahashi H, Suda T, Motoyama H, et al. Radiofrequency interstitial hyperthermia of malignant brain tumors: development of heating system. Exp Oncol 2000; 22: 186-90. 
27. Stupp R, Hegi ME, Mason WP, et al. Effects of radiotherapy with concomitant and adjuvant temozolomide versus radiotherapy alone on survival in glioblastoma in randomized phase III study: 5-year analysis of the EORTC - NCIC trial. Lancet Oncol 2009; 10: 459-66.

28. Wolbers JG. Novel strategies in glioblastoma surgery aim at safe, supra-maximum resection in conjunction with local therapies. Chin J Cancer 2014; 33: 8-15.

29. Gamaleya NF. Photodynamic therapy - effective method of treatment of patients with malignant tumors. Doktor 2003; 5: 28-31 (in Russian).

30. Hejnice AV. Photodynamic therapy the history of the method and its mechanisms. Laser Med 2007; 11: 42-6 (in Russian).

31. Kostron H, Bauer R. Management of recurrent malignant glioma-neurosurgical strategies. Wien Med Wochenschr 2011; 161: 20-1.

32. Muller PJ. Photodynamic therapy of brain tumors a work in progress. Lasers Surg Med 2006; 38: 384-9.

33. Gelfond ML. Possibilities of photodynamic therapy in oncology practice. Physical Med 2005; 15: 33-7.

34. Olyushin VE, Rostovtsev DM, Yakovenko AV, et al. Consistent application of photodiagnosis and photodynamic therapy in the treatment of patients with glial tumors (experimental application). Prof AL Polenova Russ J Neurosurg 2013; 5 (Special Issue): 206-8 (in Russian).

35. Chissov VI, Sokolov VV, Reshetov IV, et al. Photodynamic therapy of metastatic brain tumors. Russ Oncol J 2009; 2: 4-8 (in Russian).

36. Muller PJ, Wilson BC. Photodynamic therapy of malignant primary brain tumors: clinical effects, postoperative ICP and light penetration of the brain. J Photochem Photobiol 2008; 46: 929-35.

37. Muller PJ, Wilson BC. Photodynamic therapy for malignant newly diagnosed supratentorial gliomas. J Clin Laser Med Surg 1996; 14: 263-70.

38. Perria C, Capuzzo T, Cavagnaro G, et al. Fast attempts at the photodynamic treatment of human gliomas. J Neurosurg Sci 1980; 24: 119-29.

39. Kostron H, Obweeser A, Jakober R. Photodynamic therapy in neurosurgery: a review. J Photochem Photobiol B 1996; 36: 157-68.

40. Kostron H. Photodynamic diagnosis and therapy and the brain. Methods Mol Biol 2010; 635: 261-80.

41. Stylli SS, Kaye AH. Photodynamic therapy of cerebral glioma: a review. Part II. Clinical studies. J Clin Neurosci 2006; 13: 709-17.

42. Fingar VH. Vascular effects of photodynamic therapy. J Clin Laser Med Surg 1996; 14: 323-8.

43. Chen B, Pogue BW, Hoopes PJ, Hasan T. Vascular and Cellular targeting for photodynamic therapy. Crit Rev Eukaryot Gene Expr 2006; 16: 279-305.

44. Kostron H, Fiegele T, Akatuna E. Combination of "FOSCAN" mediated fluorescence guided resection and photodynamic treatment as new therapeutic concept for malignant brain tumors. Med Laser Appl 2006; 21: 285-90.

45. Marks PV, Igbaseimokumo U, Chakrabarty A. A preliminary experimental in vivo study of the effect of photodynamic therapy on human pituitary adenoma implanted in mice. Br J Neurosurg 1998; 12: 140-5.

46. Boyle RW, Dolphin D. Structure and biodistribution relationships of photodynamic sensitizers. J Photochem Photobiol 1996; 64: 469-85.

47. Stummer W, Novotny A, Stepp H, et al. Fluorescenceguided resection of glioblastoma multiforme by using 5-ami- nolovulinic acid-induced porphyrins: a prospective study in 52 consecutive patients. J Neurosurg 2000; 93: 1003-13.

48. Stummer W, Pichlmeier U, Meinel T, et al. Flourescence-guided surgery with 5-aminolevulinic acid for resection of malignant glioma: a randomized controlled multicenter phase III trial. Lancet Oncol 2006; 7: 392-401.

49. Eljamel M, Goodman C, Moseley H. ALA and photofrin fluorescence uided resection and repetitive PDT in glioblastomas multiforme: a single centre Phase III randomized controlled trial. Lasers Med Sci 2008; 23: 361-7.

50. McCaffey T, D'Cruz AK, Biel M. Effect of tumor depth and surface illumination on tumor response in patients treated with Foscan-mediated PDT. Proc Am Soc Clin Oncol 2003; 22: 503.

51. Kostron H. mTHPC-mediated photodynamic diagnosis of malignant brain tumors. Br J Neurosurg 2001; 1: 230-5.

52. Zimmermann A, Ritsch-Marte M, Kostron H. mTHPC-mediated photodynamic diagnosis of malignant brain tumors. J Photochem Photobiol 2001; 74: 611-6.

53. Olyushin VE, Komfort VE, Utilin AY, et al. Complex treatment of patients with cerebral gliomas using photodynamic therapy with photodithazine. Russ Biother J 2007; 6: 23 (in Russian).

54. Olyushin VE. Glial brain tumors: an overview of the literature and report of treatment of patients. Neurosurgery 2005; 4: 41-7 (in Russian).

55. Rostovtsev DM, Olyushin VE, Papayan GV, et al. Photodiagnosis and photodynamic therapy in cerebral gliomas surgery (experimental application). Prof AL Polenova Russ J Neurosurg 2012; 5: 33-7 (in Russian).

56. Olyushin VE. Complex treatment of patients with malignant gliomas of the cerebral hemispheres. J Russ Neurosurg 2004; 2: 123-8 (in Russian).

57. Ermakova KV, Smirnov ZS, Kubasova IY, et al. The significance of photodynamic therapy in the combined treatment of gliomas in rats. J Pract Med 2009; 36: 93-7 (in Russian).

58. Chissov VI. Photodynamic therapy of metastatic brain tumors. Ross Oncolog J 2009; 2: 4-9 (in Russian).

59. Zavadskaya TS, Holin VV. The first clinical experience with 5-aminolevulinic acid for photodynamic therapy of recurrent glioblastoma multiforme. Laser surgery. Proceedings of the conference "The introduction of modern innovative technologies in low invasion laser surgery: clinical, economic and technical aspects". V. 2. Cherkassy: Vertikal publisher SG Kandych, 2014. 162 p. (in Russian).

60. Stummer W, Stocker $\mathrm{S}$, Novotny A. In vitro and in vivo porphyrin accumulation by $\mathrm{C}_{6}$ glioma cells after exposure to 5-aminolevulinic acid. J Photochem Photobiol 1998; 45: $160-9$.

61. Schweitzer VG. Photodynamic therapy for treatment of head and neck cancer. Otolaryngol Head Neck Surg 1990; 102: $225-32$.

62. Stylli S, Kaye AH, MacGregor L, et al. Photodynamic therapy of high-grade glioma long-term survival. J Clin Neurosci 2005 ; 12: 389-98.

63. Stummer W, Gotz C, Hassan A, et al. Kinetics of photofrin II in perifocal brain edema. J Neurosurg 1993; 33: $1075-81$.

64. Stummer W, Stocker S, Wagner S. Intraoperative detection of malignant gliomas by 5-aminolovulinic acid-induced porphyrin fluorescence. J Neurosurg 1998; 42: 518-26.

65. Bernstein M, Bampoe J. Low-grade gliomas. Neurooncology. The Essentials 2000; 30: 302-8.

66. Shliakhtsin SV, Trukhachova TV, Isakau HA, et al. Pharmacokinetics and biodistribution of Photolon (Fotolon) 
in intact and tumor-bearing rats. Photodiagnosis Photodyn Ther 2009; 6: 97-104.

67. Eremeyev DV. Malignant brain tumors, obtained in rats by transplantation from human (experimental study). Bulletin Urals Med Acad Sci 2008; 4: 38-9 (in Russian).

68. Giniyatullin RW, Ismagilova ST, Eremeyev DV, et al. Morphological characteristic of changes in brain tissues after photodynamic therapy of malignant tumor reproducing in rats (experimental research). VNMT 2008; 15: 64-5 (in Russian).

69. Baryshnikov AY, Kogan EA, Khalansky AS, et al. Photodynamic therapy of brain tumors in rats using Photosens. Edn: Russ Biother Magazine 2005; 3: 52-7 (in Russian).

70. Hirschberg H, Uzal FA, Chighvinadze D, et al. Disruption of the blood-brain barrier following ALA-mediated photodynamic therapy. Lasers Surg Med 2008; 40: 535.
71. Zavadskaya TS, Taranets LP, Trompak OO. Fotolonmediated photodynamic therapy of experimental gliomas. Photobiol Photomed 2013; (1-2): 85-9.

72. Van Zaane F, Subbaiyan D, van der Ploeg-van den Heuvel A, et al. A telemetric light delivery system for metronomic photodynamic therapy (mPDT) in rats. J Biophotonics 2010; 3: 343-55.

73. Henderson BW, Waldow SM, Potter WR, Dougherty TJ. Interaction of photodynamic therapy and hyperthermia: tumor response and cell survival studies after treatment of mice in vitro. Cancer Res 1985; 45: 6071-7.

74. Master A, Livinston M, Sen Gupta A. Photodynamic nanomedicine in the treatment of solid tumors: perspectives and challenges. J Control Release 2013; 168: 88-102. 